\title{
Eco Sampah Berbasis Android
}

\author{
Nunuk Wahyuningtyas ${ }^{1}$, Titik Lusiani ${ }^{2}$, Pradita Maulidya Effendi ${ }^{3}$ \\ ${ }_{1,2}$ DIII Sistem Informasi, Universitas Dinamika \\ ${ }^{3}$ S1 Sistem Informasi, Universitas Dinamika, \\ Email: ${ }^{1} n u n u k @$ dinamika.ac.id, ${ }^{2}$ lusiani@dinamika.ac.id, ${ }^{3}$ pradita@dinamika.ac.id
}

\begin{abstract}
Abstrak: Pertumbuhan penduduk yang semakin meningkat di setiap tahunnya dapat menyebabkan permasalahan kompleks yang berdampak pada lingkungan di Kota Surabaya. Salah satunya adalah masalah pencemaran lingkungan yang diakibatkan oleh sampah. Ada beberapa masyarakat Kota Surabaya yang masih membuang sampah disembarang tempat. Hal itu disebabkan karena kurangnya kepedulian masyarakat terhadap sampah, serta adanya masyarakat yang belum mengetahui lokasi tempat sampah terdekat. Berdasarkan hal tersebut maka dirancanglah suatu aplikasi informasi tempat sampah terdekat berbasis android dengan menggunakan sistem layanan berbasis lokasi. Layanan berbasis lokasi merupkan sebuah layanan informasi yang dapat diakses dengan perangkat bergerak melalui jaringan dan mampu menampilkan posisi secara geografis yang berfungsi untuk mengidentifikasi lokasi seseorang atau objek tertentu. Aplikasi ini menghubungkan penghasil sampah rumah tangga, rumah industri, rumah sakit maupun penghasil sampah lainnya dengan pengepul lokal terdekat untuk menjual dan mengelola sampah dengan cepat. Aplikasi tersebut dapat digunakan sebagai sarana untuk menambah dan mencari lokasi tempat pembuangan sampah yang terdekat dari lokasi pengguna yang dapat diakses dengan menggunakan android dimana saja dan kapanpun. Aplikasi tersebut dapat memberikan informasi tentang sampah yang dihasilkan oleh perusahaan maupun rumah tangga sehingga dapat membantu pengolahan sampah serta transaksi jual beli sampah.
\end{abstract}

Kata Kunci: Eco Sampah, Pengepul Sampah, Aplikasi Android

\begin{abstract}
Population growth which is increasing every year can cause complex problems that have an impact on the environment in the city of Surabaya. One of them is the problem of environmental pollution caused by garbage. There are some people in Surabaya who still throw garbage everywhere. This is due to the lack of public awareness of waste, as well as the existence of people who do not know the location of the nearest trash can. Based on this, an androidbased application of the closest trash can information was designed using a location-based service system. Locationbased service is an information service that can be accessed by mobile devices via a network and is able to display geographic positions which serve to identify the location of a person or certain object. This application connects household waste producers, industrial houses, hospitals and other waste producers with the nearest local collectors to sell and manage waste quickly. This application can be used as a means to add and search for the location of the nearest garbage dump from the user's location which can be accessed using Android anywhere and anytime. This application can provide information about waste generated by companies and households so that it can help waste processing and waste buying and selling transactions.
\end{abstract}

\section{Keywords: Eco Garbage, Garbage Collectors, Android Application}

\section{PENDAHULUAN}

Sampah merupakan salah satu permasalahan yang patut untuk diperhatikan. Sampah adalah barang yang dianggap sudah tidak terpakai dan dibuang oleh pemilik / pemakai sebelumnya, tetapi bagi sebagian orang masih bisa dipakai jika dikelola dengan prosedur yang benar [1]. Sampah merupakan bagian yang tidak dapat terpisahkan dari kehidupan manusia, karena pada hakekatnya semua manusia pasti menghasilkan sampah. Volume peningkatan sampah sebanding dengan meningkatnya tingkat konsumsi manusia. Berdasarkan sifatnya sampah terdiri atas sampah organik dan sampah anorganik. Sampah organik adalah sampah yang mudah membusuk seperti sisa-sisa makanan, sayuran, daundaun kering, dan sebagainya. Sampah anorganik adalah sampah yang tidak mudah membusuk, seperti plastik wadah pembungkus makanan, kertas, plastik mainan, botol dan gelas minuman, kaleng, kayu, dan sebagainya.
Sampah jenis ini dapat didaur ulang kemudian dijual [2]. Berdasarkan bentuknya, sampah adalah bahan padat atau cairan yang sudah tidak digunakan lagi. Berdasarkan sumbernya, sampah terdiri dari sampah cair, sampah alam, dan sampah konsumsi. Sampah cair adalah bahan cairan yang telah digunakan dan dibuang ke tempat sampah. Sampah alam adalah sampah yang berada di kehidupan liar dan sudah melalui proses daur ulang alami, seperti daun-daun kering di hutan yang terurai menjadi tanah. Sampah konsumsi merupakan sampah yang dihasilkan oleh manusia sebagai pengguna barang, dengan kata lain adalah sampah-sampah yang dibuang ke tempat sampah [2].

Setiap saat sampah terus bertambah dan tanpa mengenal hari libur karena setiap makhluk terus menerus memproduksi sampah. Setiap hari sampah dihasilkan dari keluarga/rumah tangga, yang dari sisi kuantitas/jumlah biasanya menempati posisi tertinggi, 
sampah rumah sakit dan industri yang sangat berbahaya, juga sampah dari tempat-tempat umum misalnyaterminal, pasar, tempat hiburan, sekolah, kantor, dan lain lain [3]. Pemanfaatan sampah sampah harus diprioritaskan sebelum terjadinya pencemaran lingkungan yang mengganggu kesehatan masyarakat. Maka perlu adanya pengelolaan sampah, pengelolaan sampah memerlukan kegiatan yang sistematis, menyeluruh, dan berkesinambungan yang meliputi pengurangan dan penanganan sampah. Dalam UndangUndang RI Tahun 2008 Nomer 18 tentang pengelolaan sampah disebutkan bahwa pengelolaan sampah bertujuan agar menjadikan sampah sebagai sumber daya. Pencarian informasi tempat sapah berdasarkan posisi dan waktu dapat dilakukan dengan menggunakan location based service (LBS). LBS adalah suatu layanan yang menyediakan informasi berdasarkan posisi grafis sebuah perangkat [4]. LBS terbentuk dari titik perpotongan 3 teknologi, yaitu new information and communication technologies, seperti perangkat bergerak, internet, dan sistem informasi geografis. LBS memiliki 4 komponen utama, yaitu: (1) piranti mobile yang berfungsi sebagai alat bantu (tool) bagi pengguna untuk meminta informasi. Hasil dari informasi yang diminta dapat berupa teks, suara, gambar dan lain sebagainya. Piranti mobile yang dapat digunakan bisa berupa PDA, smartphone, laptop. (2) Jaringan komunikasi, yang berfungsi sebagai jalur penghubung yang dapat mengirimkan data yang dikirim oleh pengguna dari piranti mobile-nya untuk kemudian dikirimkan ke penyedia layanan dan kemudian hasil permintaan tersebut dikirimkan kembali oleh penyedia layanan kepada pengguna. (3) Positioning, dimana setiap layanan yang diberikan oleh penyedia layanan biasanya akan berdasarkan pada posisi pengguna yang meminta layanan tersebut. Oleh karena itu diperlukan komponen yang berfungsi sebagai pengolah/pemroses yang akan menentukan posisi pengguna layanan saat itu. Posisi pengguna tersebut bisa didapatkan melalui jaringan komunikasi mobile atau juga menggunakan Global Positioning System (GPS). (4) Penyedia layanan dan konten, penyedia layanan merupakan komponen LBS yang memberikan berbagai macam layanan yang bisa digunakan oleh pengguna. Sebagai contoh ketika pengguna meminta layanan agar bisa tahu posisinya saat itu, maka aplikasi dan penyedia layanan langsung memproses permintaan tersebut, mulai dari menghitung dan menentukan posisi pengguna, menemukan rute jalan, mencari data di Yellow Pages sesuai dengan permintaan, dan masih banyak lagi yang lainnya. [5].

Aplikasi mallsampah.com adalah salah satu rujukan dalam pembuatan aplikasi Eco Sampah ini, agar bisa lebih bermanfaat untuk masyarakat luas, dimana dalam aplikasi mallsampah.com jangkauannya masih belum luas. Pada aplikasi Eco Sampah terdapat fitur berlangganan yang dapat dimanfaatkan oleh perusahaan, sehingga tidak perlu melakukan pemesanan berulang kali. Keberadaan sampah dimungkinkan memiliki manfaat nilai jual yang tinggi, sehingga dengan adanya aplikasi ini masyarakat juga dapat berkreativitas dalam pengelolaan sampah secara benar dan mandiri serta ramah lingkungan. Dengan adanya aplikasi ini, diharapkan penanganan sampah yang dihasilkan oleh perusahaan maupun rumah tangga dapat menjadi lebih positif dan bahkan menguntungkan.

\section{METODE}

Metode pengembangan yang digunakan dalam Eco Sampah berbasis Android ini adalah metode ADDIE (Analisis, Design, Developer, Implementation, dan Evaluation)

\section{Observasi Lapangan}

Metode ini dilakukan untuk mengetahui seberapa sering penghasil sampah harus membuang sampahnya, serta tingkat ketergantungan penghasil sampah terhadap pengambil sampah.

\section{Proses Bisnis}

Proses bisnis untuk melakukan proses transaksi sampah antara customer dan pemulung, adalah sebagai berikut:

1. Customer mendaftar sebagai anggota diplatform Eco-Sampah. Setelah pembutan akun selesai, maka customer dapat Login ke aplikasi tersebut.

2. Customer mengisi form transaksi sampah.

3. Hasil form tersebut dikirimkan kepada pemulung yang bersangkutan sesuai dengan daftar pemesanan tertera pada aplikasi Eco-Sampah.

4. Pemulung mengambil sampah dari customer sesuai dengan alamat penjemputan.

5. Customer membayar pemesanan ke pemulung.

6. Pemulung mengambil sampah dari customer. Dan, proses transaksi sampah selesai.

\section{Android}

Android adalah sistem operasi untuk telepon seluler yang berbasis Linux [6]. Android menyediakan platform terbuka bagi para pengembang buat menciptakan aplikasi mereka sendiri untuk digunakan oleh bermacam peranti bergerak. Awalnya, Google Inc. membeli Android Inc., pendatang baru yang membuat peranti lunak untuk ponsel. Kemudian untuk mengembangkan Android, dibentuklah Open Handset Alliance, konsorsium dari 34 perusahaan peranti keras, peranti lunak, dan telekomunikasi, termasuk Google, HTC, Intel, Motorola, Qualcomm, T-Mobile, dan Nvidia.

\section{Desain Form}

Desain form yang telah dibangun meliputi master dan transaksi, diantaranya adalah:

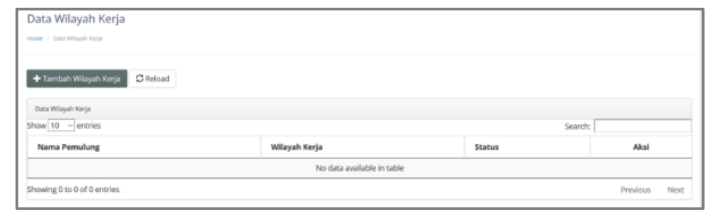

Gambar 1. Form Master Wilayah Kerja 
Pada master wilayah kerja ini meliputi kota atau kabupaten wilayah jangkauan sampah.

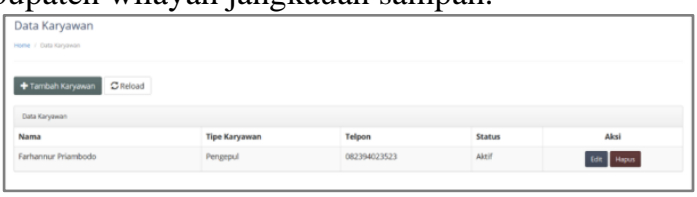

Gambar 2. Form Data karyawan

Pada Data karyawan ini meliputi data admin dan juga data pemulung.

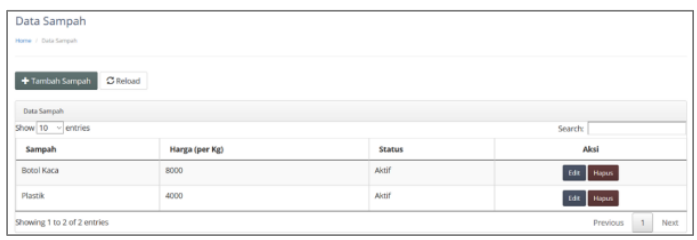

Gambar 3. Form master sampah

Pada halaman sampah terdapat tampilan table data dari sampah, dengan beberapa menu seperti Tambah untuk menambah data baru dan juga pada table data terdapat tombol Edit untuk mengubah data.

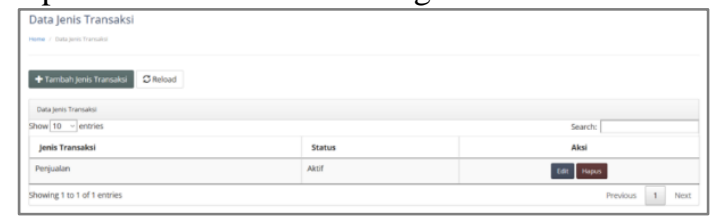

Gambar 4. Form Transaksi

Pada form transaksi ini custumer dapat memilih jenis transaksi, diantaranya (1) penjualan sampah kepada pemulung. (2) permintaan sampah kepada pengepul, dan bisa juga (3) mengelola profile.
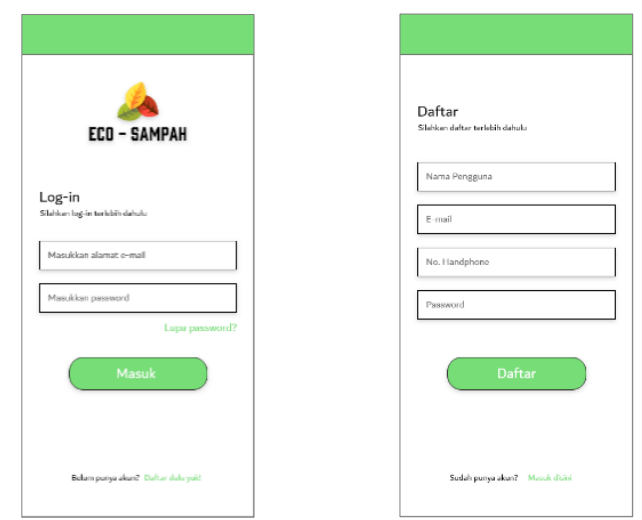

Gambar 5. Hal. Login Gambar 6. Hal Daftar

Halaman Login digunakan bagi customer yang sudah memiliki user akses, sedangkan bagi customer yang belum memiliki, maka menggunakan halaman daftar.

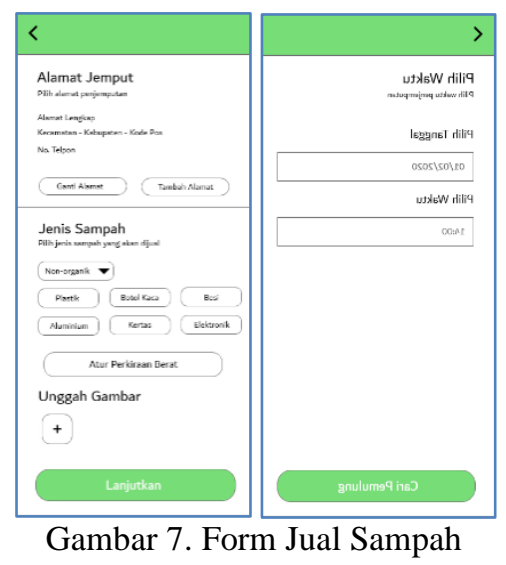

Pada halaman jual sampah, customer mengisi data sampah yang akan dijual seperti sampah apa saja yang akan dijual, perkiraan berat pada tiap jenis sampah, dan gambar; lalu memilih alamat sebagai alamat serta waktu untuk menjemput sampah yang dijual.

Pada halaman selanjutnya adalah tampilan dari riwayat penjualan sampah yang menampilkan list transaksi jual sampah ataupun beli sampah yang telah dilakukan oleh customer. Sedangkan untuk halaman profil, dapat digunakan customer untuk mengelola akun dan informasi bantuan.
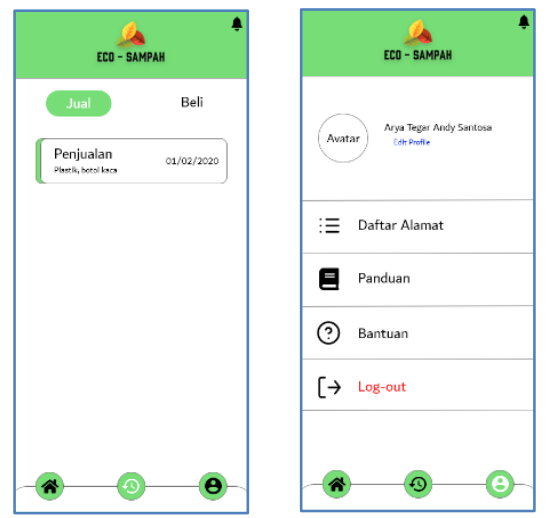

Gambar 8. Riwayat penjualan Sampah dan halaman profil

\section{HASIL DAN PEMBAHASAN}

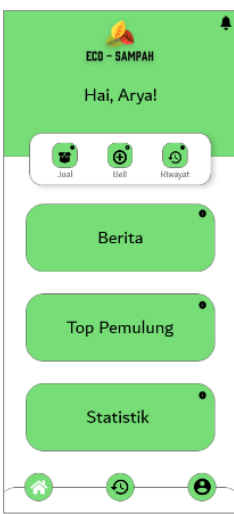

Gambar 9. Tampilan Beranda 
Dalam penelitian ini dihasilkan sebuah aplikasi Eco Sampah berbasis android yang bertujuan untuk memberikan informasi tentang informasi penjualan sampah, pembelian sampah serta informasi sampah yang dihasilkan oleh perusahaan, instansi maupun rumah tangga.

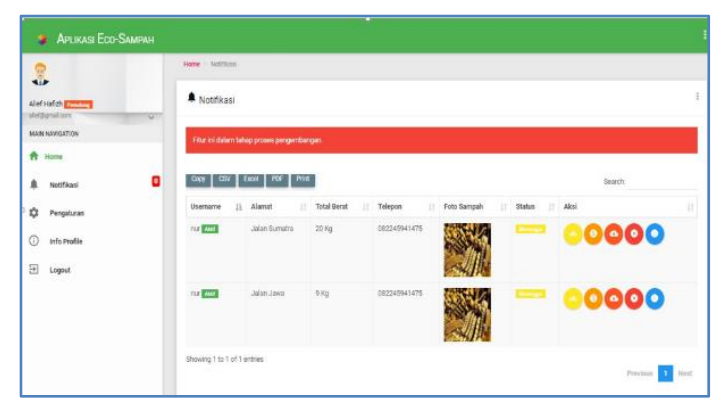

Gambar 9. Transaksi di Menu Pemulung

Pada saat akses menggunakan user pemulung, akan menunjukkan data sampah yang harus diambil atau yang sudah diambil oleh pemulung,

\section{KESIMPULAN DAN SARAN}

Berdasarkan penelitian yang telah dilakukan dalam implementasi pengembangan aplikasi Eco Sampah berbasis android, maka dapat disimpulkan metode pengembangan yang digunakan dalam pengembangan Eco Sampah ini yaitu dengan metode Analisis Design, Developer, Implementation, dan Evaluation (ADDIE). Berdasarkan hasil kuisioner yang didapat, aplikasi ini dapat menjadi solusi elternatif yang efektif untuk pengurangan (reuse, reduce serta recycle) dan penanganan masalah sampah (pemilahan, pengumpulan, pengangkutan). Dengan menggunakan aplikasi ini, saling keuntungan baik dari sisi customer maupun dari sisi pengepul. Dalam aplikasi ini dapat dikembangkan dengan menambahkan fitur berlangganan, sehingga dari pihak customer tidak perlu melakukan request pengambilan sampah setiap hari, sedangkan dari pihak pengepul atau pemulung sudah memiliki jadwal rutin untuk pengambilan sampah.

\section{Ucapan Terimakasih}

Terimakasih disampaikan kepada pihak lembaga Universitas Dinamika melalui Departemen Penelitian dan Pengabdian Masyarakat (PPM) atas dana hibah yang telah dialokasikan untuk menyelesaikan penelitian ini.

\section{DAFTAR PUSTAKA}

[1] Nugroho panji, 2013. Panduan membuat kompos cair. Jakarta: pustaka baru press.

[2] Lianandari, Putri. (2011). Menjadi Jutawan Dari Sampah Plastik: Menyulap Sampah Plastik Menjadi Kreasi Unik dan Cantik. Yogyakarta: Araska.

[3] Suwerda, B. (2012). Bank Sampah (Kajian Teori dan Penerapan) Disertai Penerapan Bank Sampah "Gemah Ripah" di Dusun Badegan Bantul. Yogyakarta: Pustaka Rihama
[4] Amit Kushwaha, Vineet Kushwaha. 2011. Location Based Services using Android Mobile Operating System. International Journal of Advances in Engineering \& Technology. Vol. 1,Issue 1,(March 2011): 14-20.

[5] Badrul Anwar, Hendra Jaya, Putra Indra Kusuma, "Implementasi Location Based Service Berbasis Android Untuk Mengetahui Posisi User", Jurnal SAINTIKOM Vol.13, No. 2, Mei 2014, ISSN : 1978-6603

[6] Safaat H, Nasrudin. 2011. Pemrograman Aplikasi Mobile Smarthphone dan Tablet PC Berbasis Android. Bandung: Informatika 